\title{
RELAÇÕES DE TRABALHO NO TERCEIRO SETOR: UM ESTUDO EM ASSOCIAÇÕES DE PAIS E AMIGOS DOS EXCEPCIONAIS (APAEs)
}

\section{LABOR RELATIONS IN THE THIRD SECTOR: A STUDY IN ASSOCIATIONS OF PARENTS AND FRIENDS OF THE MENTALLY HANDICAPPED (APAE)}

\author{
Amanda Burchert ${ }^{1}$ \\ Denise Macedo Ziliotto ${ }^{2}$
}

\section{RESUMO}

O objetivo deste artigo é identificar aspectos da relação de trabalho existentes em organizações do terceiro setor. A pesquisa se constituiu por uma análise qualitativa e exploratória a partir de entrevistas com gestores de APAEs. Os resultados obtidos indicam a predominância de práticas de contratação e demissão como modalidades de mediação dos vínculos, realizada em parceria com as prefeituras locais. A cedência de servidores pelo município, a ausência de profissionais qualificados na região pesquisada e a identificação dos trabalhadores com as demandas e características das instituições são desafios presentes nestas organizações. Diferentemente do aspecto majoritário do terceiro setor, nas instituições pesquisadas não há membros voluntários em virtude do receio de ações trabalhistas e reduzida articulação da comunidade. Observa-se que a diretoria tem participação efetiva nas decisões, em conjunto com a coordenação pedagógica, e há multifuncionalidade nos processos de trabalho em função do quadro de pessoal restrito.

PALAVRAS-CHAVE: APAE - Relações de Trabalho - Terceiro Setor.

\begin{abstract}
This paper aims to identify aspects of labor relations in third sector organizations. The research involves a qualitative, exploratory analysis of interviews with APAE managers. The results have shown the prevalence of hiring and firing practices as modalities of bond mediation performed together with local city halls. The cession of workers by the cities, the absence of qualified professionals in the surveyed region, and the identification of workers with the demands and
\end{abstract}


characteristics of the institutions are the challenges found in those organizations. Unlike the third sector, there are no volunteers in the surveyed institutions due to the fear of labor lawsuits and reduced community involvement. The board of directors has an effective participation in decisionmaking along with the pedagogical coordination; as the staff is small, workers perform several functions.

KEYWORDS: APAE - Labor Relations - Third Sector.

\section{INTRODUÇÃO}

O terceiro setor tem se constituído como espaço para a geração de trabalho e renda, sendo de profunda importância no Brasil e no mundo (PEREIRA; MORAES; MATTOS; PALMISANO, 2013). As oportunidades que vêm desta área não são somente uma maneira de solucionar problemas sociais, mas também criar novos empregos e ajudar em questões estruturais do Brasil (ASSIS; VIEGAS e CKAGNAZAROFF (2012)).

O terceiro setor surgiu da necessidade de preencher o espaço deixado pelo Estado e pelas empresas privadas, atendendo aos problemas sociais que foram surgindo com as transformações da sociedade, compreendendo também um espaço de atuação profissional (SILVA, 2010; PEREIRA et al, 2013).

Para Pinto (2006), as instituições do terceiro setor têm realizado importantes mobilizações por direitos, formação de redes e programas de empoderamento. Têm sido também responsáveis pela presença no campo político de temas que historicamente encontraram resistência no interior dos partidos políticos, como a questão dos direitos das mulheres. Entretanto, assinala a autora, estas organizações não podem ser vistas como substitutas de partidos políticos, do Estado ou mesmo dos movimentos sociais. Suas ações têm limites, entre eles o fato das instituições serem fragmentadas, pois atingem o conjunto da sociedade de forma limitada e dependem de financiamentos pontuais.

Para uma melhor compreensão deste tema, este artigo é guiado pelo seguinte objetivo: identificar aspectos presentes nas relações de trabalho em organizações do terceiro setor. A pesquisa realizada é de natureza qualitativa e ocorreu por meio de entrevistas com gestoras de APAEs, instituições que atendem sujeitos com necessidades especiais, em cidades do RS. 
Para desenvolvimento da investigação, primeiramente procede-se a contextualização do terceiro setor no país, em seguida explicita-se o método utilizado na pesquisa, são apresentados e analisados os resultados e finaliza-se com as considerações finais que sintetizam o percurso realizado.

\section{CONTEXTUALIZANDO O TERCEIRO SETOR}

Concebe-se terceiro setor como um conjunto de iniciativas e organizações privadas que têm suas bases no trabalho voluntário e de associações, orientados por valores definidos em uma missão e atuando em prol das necessidades humanas, direitos e garantias sociais (CABRAL, 2007). Ao longo da história, percebe-se que o Estado não consegue garantir o básico da necessidade social, incitando algumas organizações a atuarem como um terceiro setor, que está muito além do estatal e do privado, estando presente no social (DINIZ, 2003).

Um desafio presente para o terceiro setor é gerir o conhecimento. Por ser um setor de informalidade e muita rotatividade, os conhecimentos são tácitos e informais, o que dificulta muitos processos. É preciso reaprender os procedimentos quando acontece a saída de algum membro, pois em muitos casos não há compartilhamento do conhecimento com as demais pessoas. Neste sentido, o gestor tem papel fundamental de criar espaços para registrar a memória institucional, pois ela é o capital social que necessita ser sistematizado e difundido para a sociedade (PEREIRA et al, 2013).

As organizações não governamentais (ONGs) são agentes organizadores da sociedade, sendo mais espontâneos e menos burocráticos, fundamentais na constituição da cidadania, tornando-se também fiscalizadores sobre a política no que tange a assuntos públicos (INSTITUTO PRO BONO, 2005). Estas organizações têm buscado maneiras de educar, formar e capacitar os indivíduos através de vários focos de atuação como, por exemplo: educação; saúde; cultura; comunidade; apoio à criança e ao adolescente; voluntariado; apoio aos portadores de deficiências dentre outras áreas. (TACHIZAWA; POZO; ALVES, 2012). As ONGs surgem na década de 70 em resposta ao regime militar e ao cerceamento dos direitos humanos, ampliando paulatinamente suas pautas, atuando em frentes como a questão da sustentabilidade,da discriminação racial, dos preconceitos sociais e da pobreza (SILVA, 2010; TACHIZAWA, 2010). 
No Brasil as ONGs começaram a ganhar importância desde que o Estado deixou de ser o único a implementar políticas sociais. Dentre todas as instituições que se encontram em atuação, percebe-se que seu público é diversificado, atendendo diversos grupos sociais (TACHIZAWA; POZO; ALVES, 2012). Como decorrência, foram criadas associações para dar suporte ao Terceiro Setor, como o Grupo de Institutos, Fundações e Empresas (GIFE, 2015), o Centro de Estudos do Terceiro Setor (CETS), e a Rede de Informações para o Terceiro Setor (RITS) (SILVA, 2010).

Segundo Menescal (1996), as ONGs brasileiras trabalham especialmente em nível político, pois buscam influenciar políticas governamentais que tragam benefícios à sociedade brasileira. Atuam como organizações que apoiam grupos e movimentos populares, tecendo redes de solidariedade que o Estado e o mercado não são capazes de estabelecer. A autora alerta, entretanto, para a importância da atuação articulada entre as instituições, para haver mobilização entre os diferentes grupos e movimentos da sociedade civil.

\section{O TRABALHO NO TERCEIRO SETOR}

Apesar de o terceiro setor possuir não visar lucro e constituir-se coletivamente, não quer dizer que não tenha a necessidade de ter uma boa gestão, pois também precisa oferecer condições aos seus colaboradores (ASSIS et al, 2012). O terceiro setor está em continuo crescimento, exigindo de seus gestores - para serem efetivos - uma transformação em sua forma gerencial para as práticas sociais (SOARES; MELO 2010). E ser efetivo compreende a capacidade de atender as necessidades e expectativas da sociedade (TENÓRIO, 2004). E se há organizações com medo de gerenciar, por outro lado existem as que percebem a importância das relações institucionais, pois seria incoerente não fazer dentro do próprio ambiente de trabalho as condições que pleiteia no social (ASSIS et $\mathrm{al}, 2012)$.

As atividades e funções comuns da administração que são desenvolvidas no terceiro setor são semelhantes às dos setores público e privado, o que se destaca é a questão da parte social. O trabalho social além de ser uma característica da gestão que as organizações sociais devem ter é também o motivo da existência das mesmas e norteiam formas específicas de realizar a gestão na sociedade (SOARES; MELO 2010). Tachizawa (2010) faz contraponto ao afirmar que a gestão dos 
programas sociais e do terceiro setor é diferente da gestão no setor privado e que, um ótimo executivo não necessariamente será um bom gestor social.

As mudanças que ocorreram na área social e econômica fizeram com que houvesse um contexto social e político diferente, permitindo que as organizações do terceiro setor crescessem e se tornassem mais importantes. Diante de tantas transformações, estas organizações também tiveram que modificar sua gestão, para garantir que seu trabalho continuasse. Outra questão enfrentada é o aumento na concorrência por recursos financeiros, vindos dos setores públicos e privados. Por esses motivos compreende-se porque a gestão é importante para superar as necessidades e enfrentar a realidade do terceiro setor (ASSIS et al, 2012).

Há uma demanda de interessados em atuar no setor social, mas as organizações sociais precisam definir que funcionário contribui para seu contexto, dando importância para o comprometimento da pessoa com os valores, objetivos e missão da ONG (TACHIZAWA, 2010). Conhecer o que motiva o indivíduo a ser voluntário, pode contribuir para a gestão do problema de grande rotatividade que há no terceiro setor. Essas informações favorecem o planejamento de estratégias para os gestores acompanharem o desenvolvimento dos membros nas instituições (CAVALCANTE; SOUZA; MÓL 2015).

A criação de projetos também é uma maneira de alcançar os objetivos e responder à missão das ONGs. Com o desenvolvimento da capacidade de gerir, as organizações sociais envolvem-se em vários projetos e conseguem administrar os recursos materiais, financeiros e de pessoas, tendo em cada área pessoas responsáveis pela qualidade e tarefas (PEREIRA et al, 2013). Uma questão importante dentro da gestão no terceiro setor refere-se ao controle das suas atividades, sobre os recursos usados e serviços ofertados. Comparar as ações que foram planejadas com os resultados que estão sendo obtidos, e nesta análise solucionar problemas e corrigir erros, para que os objetivos estejam alinhados a missão e aos valores da organização, podem garantir seu futuro (TENÓRIO, 2004).

\section{MÉTODO}

A pesquisa realizada foi de natureza qualitativa e exploratória, pois busca abordar o tema a partir da aproximação e análise de aspectos do problema investigado - as relações de trabalho no 
terceiro setor. O método baseia-se em pequenas amostras que conseguem proporcionar uma compreensão do contexto do problema em questão (MALHOTRA, 2012), justificando-se pela capacidade de analisar o conteúdo e entender o contexto em que a investigação é realizada. Lakatos e Marconi (2003) também afirmam que os objetivos da pesquisa exploratória são a formulação de questões ou problemas a fim de gerarem hipóteses, trazendo mais conhecimento sobre o ambiente estudado.

O instrumento de coleta de dados é a entrevista, realizada com gestores de instituições do terceiro setor localizadas na região centro sul do estado do RS. A entrevista é uma técnica em que o pesquisador apresenta-se ao investigado, formulando perguntas para obter dados que possam colaborar com a pesquisa, sendo uma forma de interação social segundo Gil (2012). Trata-se de uma conversa face a face de maneira estruturada e que permite a coleta de dados necessários verbalmente (LAKATOS, MARCONI, 2003).

São critérios de inclusão na investigação os participantes que estão inseridos nesta região geográfica, a formalidade jurídica da instituição, atender aos requisitos como organização do terceiro setor e assinatura do TCLE. Como critérios de exclusão figuram o não cadastramento junto à secretaria de assistência social das prefeituras (não regularização jurídica), não ser gestor da instituição e não estar localizado na região de estudo do pesquisador. Após transcrição e leituras sistemáticas do material coletado, procedeu-se a análise e categorização do conteúdo das entrevistas.

\section{APRESENTAÇÃO E ANÁLISE DOS RESULTADOS}

A pesquisa foi desenvolvida naregião centro sul do RS, que compreende 17 municípios. Sua economia está baseada principalmente na agricultura e comércio, buscando reforço na área de turismo, pois também é conhecida como Costa Doce. Evidencia-se a presença da colonização alemã, italiana e polonesa na gastronomia, no folclore, na cultura agrícola, na linguagem e nos hábitos da população.

Inicialmente foram investigadas instituições do terceiro setor que possuíssem características exigidas para a participação na pesquisa em sete municípios - Sertão Santana, Barão do Triunfo, Barra do Ribeiro, Tapes, Mariana Pimentel, Cerro Grande do Sul e Camaquã, que se circunscrevem 
a região em estudo. A partir de contatos com as prefeituras, com assistentes sociais, psicólogos e sites de busca foram identificadas cinco instituições, sendo que quatro aceitaram participar da pesquisa.

Um primeiro achado da pesquisa, ao buscar organizações do terceiro setor, foi a característica única das organizações identificadas na região que circunscrevia a investigação: eram Associações de Pais e Amigos dos Excepcionais (APAEs), não havendo outras instituições ativas e regularizadas nos municípios investigados. Por tratarem de cidades pequenas - em média com 22.890 mil habitantes $^{3}$ - pode-se levantar algumas hipóteses para esta restrita ocorrência: o atendimento das necessidades mais emergenciais da população pelos municípios maiores ou mesmo pelos serviços de referência na capital, a dificuldade de organização da sociedade nestas regiões para suprirem demandas regionais e mesmo a ausência de projetos de promoção da saúde e cidadania presente nestas cidades. Neste sentido é emblemática a existência da APAE, que oferece escolarização e atendimentos em saúde para os deficientes, população que enfrenta exclusão social, o que talvez tivesse mobilizado estas comunidades para a existência destas organizações.

A Apae é uma associação civil, de assistência social, de caráter filantrópico, com atuação nas áreas da prevenção, educação, saúde, trabalho/profissionalização, garantia de direitos, esporte, cultura/lazer, de estudo e pesquisa e outros, sem fins lucrativos e de fins não econômicos, com duração indeterminada, tendo sede e foro no município em que estiver situada. A APAE, segundo sua entidade federativa, tem por missão promover e articular ações de defesa de direitos, prevenção, orientação, prestação de serviços, apoio à família, direcionadas à melhoria da qualidade de vida da pessoa com deficiência e à construção de uma sociedade justa e solidária (FENAPAES, 2014).

A partir da identificação das organizações, foram realizados contatos e agendadas as entrevistas com as diretoras das APAES; posteriormente se observa que são também professoras na instituição. São apresentadas as participantes a seguir:

A E1 tem formação em Educação Física, está há oito anos na APAE. Esta unidade tem dez anos de funcionamento, possui o certificado de Entidades Beneficentes da Assistência Social CEBAS - e atende hoje 21 alunos com deficiência intelectual. Trabalha em regime CLT com quatro funcionários contratados pela entidade e possui três cedidos pela prefeitura municipal.

A E2 possui magistério, está há seis anos na APAE. A associação possui 38 anos de funcionamento e atende 20 alunos com diversas necessidades especiais - síndrome de down, 
deficiência intelectual, deficiência física e auditiva. Atualmente são sete profissionais contratados (nenhum cedido pela prefeitura) e possui convênio com o município.

A E3 possui formação em Educação Especial, trabalha há nove anos na APAE. A associação possui dez anos de funcionamento, é filantrópica, possui as certificações e também recebe pelo Programa Dinheiro Direto na Escola (PDDE). Atende 21 alunos, especialmente com síndrome de down e autistas. Possui seis funcionários e tem convênio com a Unimed, pois não oferece atendimentos clínicos para seus alunos.

A E4 tem formação em Educação Especial, atua há um ano na associação como diretora da escola de educação especial na APAE. A instituição possui 43 anos de atuação na região, possuindo filantropia e todos demais certificados, devidamente regularizada e também recebe pelo PDDE. A organização está composta escola de educação especial e pela clinica de reabilitação, sendo estas duas mantidas pela associação. São 70 funcionários, entre contratados, estagiários do CIEE e cedidos das prefeituras. Hoje atende em torno de 250 alunos, com síndrome de down, autismo, paralisia cerebral e outras deficiências; também prestam atendimento aos municípios vizinhos que não possuem APAE.

A seguir são apresentadas as contribuições dos participantes para a investigação. A partir da leitura sistemática das entrevistas, foram constituídas as seguintes categorias de análise: Estrutura e funcionamento das APAES, Processos de trabalho, e Recursos e limitações.

\section{ESTRUTURA E FUNCIONAMENTO DAS APAES}

As APAES investigadas possuem a mesma estrutura: diretoria administrativa, tesoureiros, conselhos e fiscais, sendo todos os colaboradores voluntários e escolhidos através de eleições. Na área pedagógica há um diretor responsável pela educação dos alunos e acompanhamento de professores. As diretorias são formadas por várias pessoas, porém o que se percebe é que nem todos são atuantes como diz a E4:

Os que mais atuam estão mais aqui dentro da casa é o presidente, o vice-presidente e o financeiro. São esses três, os três que estão assim mais ligados com a casa e os demais vêm quando tem reuniões, quando tem alguma atividade, quando tem alguma festividade. Aí eles estão juntos, mas assim, envolvidos no trabalho realmente, é o presidente, o vice e o tesoureiro. 
Embora na constituição das APAES figurem vários membros, são poucos os colaboradores que realmente atuam nas associações, mas estes se fazem presentes e são importantes para o bom funcionamento da instituição e principalmente de sua gestão. Em toda pesquisa evidencia-se a presença do diretor em todas as decisões, desde a contratação de funcionários, da busca por novas técnicas, demissão e planejamento de eventos, como informam:

Fazemos diversos eventos e nós professores e funcionários que organizamos [...] mas quando o evento é maior se faz uma reunião da diretoria em turno separado e também cabe a eles todas as decisões maiores [...] quando tem uma dificuldade, alguma questão mais difícil pra resolver, senta todo mundo, para tentar resolver da melhor forma e se aceita opiniões [...]quando há questões assim de um aluno, alguma coisa a diretoria ajuda, se envolve (E1).

O que é parte assim pedagógica eu mesmo decido. Agora, quando é alguma coisa que tenha que decidir sobre uma compra ou fazer uma rifa - isso tudo é junto com a diretoria, a gente decide junto. A gente discute aqui dentro, e sempre a gente vai até o presidente pra conversar e buscar uma solução juntos. A gente nunca decide alguma coisa sem que a diretoria administrativa saiba, até porque é uma hierarquia. A gente sabe que precisa estar junto, porque eu acho que até mais pessoas juntas vão ter maior capacidade de resolver (E2).

Em primeiro lugar a conversa: se a gente está com algum problema é resolvido cara a cara, a gente não tem que esconder embaixo do tapete [...] e às vezes a gente faz reunião com a diretoria, fica a reunião com a diretoria. Eu participo sempre da reunião, mas eu não preciso trazer tudo o que eles falam para o pessoal que trabalha, tem certas coisas que não precisa saber. Claro que se me perguntam alguma coisa assim, a gente sempre responde, mas tem certas coisas que não condizem, mas não quer dizer que a gente tá escondendo, é que não precisa. (E3).

O nosso presidente ele é bastante parceiro, ele não é um presidente que vem e assina papéis [...] então é uma pessoa que busca conhecer todo o andar da casa, todas as coisas que a gente faz. A gente passa pra ele tudo, antes de qualquer decisão que nós vamos tomar a gente senta com ele e troca ideias. [...]É tudo em sintonia, senão não tem como funcionar porque o trabalho é em conjunto, nós somos uma coisa única, onde tem esses braços, digamos. (E4).

Em relação às decisões administrativas, E4 também afirma a efetividade das ações do presidente, especialmente nesta unidade:

Quando alguma coisa assim administrativa - de repente eu ter que mexer em alguém - é sempre com o presidente. Se for demitir, sempre a gente passa para o presidente e senta em conjunto e tenta solucionar.[...] se sãocoisas do dia a dia eu tenho autonomia pra tomar todas as decisões com professor, aluno, com os pais [...] as decisões não saem únicas de um setor e sim, a gente vai buscar ajuda pra refletir naquela situação ali, pra ver o que vai ficar melhor. (E4) 
Outra situação que acontece nas APAES entrevistadas é a prestação de contas para as prefeituras que cedem funcionários, sendo necessário realizar rotinas trabalhistas, como registro do ponto, previsão de férias, atestados de saúde, dentro outras informações que são repassadas para técnicos das prefeituras mensalmente.E1 afirma o rigorismo da contabilidade para não ocorrerem problemas relativos à pessoal, observando os direitos trabalhistas, pois o receio de ações judiciais é significativo.

Tachizawa et al (2012) afirmam que as ONGs precisam adaptar-se às mudanças e criar seus modelos de gestão para se desenvolverem; cada instituição que faz parte do terceiro setor tem uma característica diferente e é organizada de acordo com suas peculiaridades. No caso das APAES pesquisadas, sua estrutura é formada por diretorias - administrativa e pedagógica - onde a primeira busca recursos e cedências de pessoal, e a segunda centra-se na relação com os professores.

\section{PROCESSOS DE TRABALHO}

A investigação evidenciou que as APAES adotam algumas práticas de gestão, mas não evidenciam intencionalidade no desenvolvimento de políticas para com seus membros. Percebe-se dualidade entre os processos realizados na instituição e nas prefeituras, visto que alguns aspectos são deliberados por uma instância e outros já são da competência do órgão público:

\footnotetext{
O setor pessoal, que tem na nossa prefeitura, cuida da nossa vida pessoal. Aqui na casa nós temos o pessoal das secretárias, são as secretárias que cuidam de toda parte da vida pessoal de todos os professores que estão aqui, mesmo nós que somos cedidos eles possuem ali toda uma organização das nossas formações, toda nossa documentação está ali na secretária (E4).
}

As entrevistadas E2 e E3 afirmaram não ter conhecimento de políticas específicas em relação aos trabalhadores e acreditam que seria interessante contar com o apoio neste âmbito. A partir dos processos relatados pelas participantes, observa-seque as ações existentes estão norteadas principalmente pelas situações de seleção, contratação e demissão. Com relação aos processos de contratação, as participantes relatam como realizam este processo: 
Primeiro eu converso com a pessoa, coloco pra ela todas as dificuldades que a APAE tem pra pessoa já vir pra cá sabendo, oque pode enfrentar, o que pode acontecer. Depois então o presidente também conversa com ela, com a pessoa. Não passa por teste nenhum, simplesmente a gente conversa com ela, tanto a diretora quanto o presidente e por ai a gente contrata (...) a gente pede o grau de formação que possui, e a única coisa que a gente exige é a pessoa que esteja pelo menos começando uma profissão (...) como é um município bem pequeno, a gente conhece todo mundo. Então a gente tem informações se já trabalhou numa escola ou numa creche, alguma coisa assim. (E2)

A gente tem que ver se a pessoa vai se adequar, porque uma vez teve uma professora que veio trabalhar aqui - ela é uma ótima professora - só que ela passou uma semana inteira chorando... Eu acho que tu te adequas ao que tu gostas,no que tu vais te sentir bem ..só que ela não se sentiu bem aqui. A gente não culpa, porque tem certas situações aqui dentro que tu tens que olhar, mas não ver com olhos de pena, sabe? (...) Quando é a gente que vai contratar, fazemos um tempo de experiência antes de assinar a carteira, para saber se a pessoa vai se adequar ao ambiente de trabalho, contamos com a ajuda da psicóloga da cidade, e para contratação passa por entrevista com nós duas, a pessoa traz o currículo e fala sobre seus interesses e se tem experiência, às vezes nem passa por ela, procuro ver a forma como trabalha e explicar como funciona a rotina aqui dentro (E3).

E4 menciona a contratação de estagiários via Centro de Integração Empresa-Escola (CIEE), onde são enviados currículos para serem analisados e a partir do retorno, a instituição mediadora faz a contratação. Optam por realizar um período de adaptação para ambas as partes, para depois formalizarem o vínculo, quando se confirma que se encaixa no perfil da instituição. São preferidos estagiários que estejam fazendo Pedagogia ou curso na área de educação.

As participantes relatam que buscam conversar e orientar os futuros profissionais no processo de seleção. Cada diretora tem sua forma de gestão, mas todas prevêm um tempo de adaptação e buscam pessoas que se identifique mcom a missão da instituição. Ainda no processo de seleção, há outro desafio para essas entidades: as cedências de profissionais. Especialmente uma APAE possui poucos membros e apresenta duas questões importantes, as cedências da prefeitura e os problemas de seleção em cidades do interior:

A cedência do município de professor; tem lá um professor que sobrou, um professor que sobrou enão querem e a escola mandou pra cá... Já teve essa experiência da APAE: manda de volta,embora porque não deu certo. Mas daí, no caso, não fomos nós que contratamos esse professor $(\mathrm{E} 1)$.

E a respeito da seleção, a entrevistada menciona um processo seletivo, onde o candidato escolhido tinha escolaridade menor, mas era conhecido do diretor, evidenciando interferências existentes no processo. A E4 assinala também a dificuldade relativa às cedências: 
Às vezes vem um profissional que não é aquele que eu escolhi - não pode ser qualquer um profissional, tem que ser assim alguém que tenha dentro, que entre dentro do nosso perfil é aquele professor que daqui a pouco tá dando problema lá [...] e eles reservam aquele pra nós e colocam na cedência. A gente faz essa fala - a gente não quer aquele professor que daqui a pouco pra vocês não tá legal -para se verem livre vão mandar pra lá na cedência... A gente não quer esse, a gente quer o melhor.

Em relação à rotatividade, um desafio para o terceiro setor, pois no momento em que acontecem os desligamentos aquele conhecimento se perde, pois dificilmente foi transmitido para outra pessoa (PEREIRA et al, 2013), esta realidade não foi evidenciada na pesquisa, pois de acordo com o relato dos entrevistados os funcionários tendem a permanecer na instituição como diz a E4:

Os funcionários não trocam muito, os nossos funcionários estão há muito tempo aqui. Agora que entrou uma funcionária nova e tem outra que já está se aposentando agora aqui dentro e ela trabalhou sempre aqui, então não tem muitas trocas nelas; nossas trocas maiores são os monitores mesmo. Quando acaba o CIEE de dois anos, e alguns a gente contrata. (E4)

E3 também relata que há permanência de profissionais por anos e a importância deste conhecimento para a instituição: “C. fez quinze anos, iniciou com a APAE... a gente goza dela, dizendo que é o nosso museu. Ela iniciou e ela permanece na APAE, então ela tem um bom conhecimento".(E3). As entrevistadas E1 e E2 não mencionaram sobre a rotatividade, em seus relatos comentam sobre as contratações e demissões que funcionam de acordo com suas necessidades.

O relato de E3 identifica outra especificidade encontrada no terceiro setor dessa região: a exdiretora atua como voluntária, e repassa o seu conhecimento para a atual. Muitos funcionários saem, mas acabam pedindo para voltar como diz E1: "Vai sair um funcionário, normalmente se abre um processo seletivo ou algum ex-funcionário já pediu pra voltar [...] às vezes a pessoa quer sair por algum motivo, que nem eu já fui funcionária da APAE hoje eu sou cedida da prefeitura”.

E há aqueles que apesar de todas as incertezas de trabalhar neste setor, permanecem unidos em prol do seu objetivo:

Há pessoas dedicadas, que muitas vezes a gente passou por situações de não saber nem se ia receber no mês, e essas pessoas não deixaram de vir trabalhar, nunca deixaram de vir, 
totalmente comprometidas [...] mas graças a Deus nenhuma me deixou na mão, todos aqui junto comigo. (E2)

A baixa rotatividade nas instituições pesquisadas pode ser atribuída à restrita presença de profissionais qualificados na região, aos contratos de trabalho formais e às oportunidades profissionais restritas nestes municípios; outro ponto a se destacar é que muitas pessoas não tem estrutura emocional, não suportam as dificuldades e o trabalho junto à população atendida, como se observa no depoimento das gestoras;

Só que a gente tem que ir testando também, a gente tem que ver se a pessoa vai se adequar [...]a gente enxerga os nossos alunos como qualquer aluno de qualquer escola, e tem pessoas que não enxergam assim. Se tu entras aqui pra dentro e tratas com pena, tu já estás trabalhando errado com eles e tem que trabalhar por igual. (E3)

Nós notávamos que muitas vezes eles eram contratados, mas eles não conseguiam suportar o trabalho aqui. Eles não conseguiam, mexia muito com o emocional; o emocional deles ficava fragilizado diante das necessidades das crianças eles se fragilizavam (E4).

Para Tachizawa (2010) é preciso criar políticas para o desenvolvimento dos profissionais, pois quanto mais estruturado e preocupado com seus colaboradores, mais qualificado se torna o serviço prestado pelas associações, ponto fortemente evidenciado por E4:

Por isso a gente tem um grupo com as psicólogas, então elas têm as professoras de quinze em quinze dias [...]é um trabalho que exige do professor uma paciência, um equilíbrio muito grande porque vem muitas coisas familiares e eles se comovem com situações de casa, de família. Eu acho que isso é o nosso maior desafio manter as gurias motivadas com vontade de ensinar e de acreditar que eles podem aprender(E4).

\section{RECURSOS E LIMITAÇÕES}

As associações com menos tempo de atuação e estrutura ainda restrita, afirmamque em alguns é preciso que todos participem das outras funções:

Aqui todo mundo ajuda em tudo.Quando a gente é contratadojá se fala que é uma entidade [...] muitas vezes tá faltando alguém aqui na secretaria e vai ter que sair da sala e atender a pessoa que chegou ou ajudar a limpar [...]todo mundo que entra aqui já sabe que tem esse 
comprometimento de ajudar em tudo (...) então a gente procura interagir todo mundo junto, buscar essa união pra poder sair um trabalho legal. (E1).

Então a gente tem que ter parceria, todo mundo está aqui dentro sabe que faltou a merendeira a gente vai pra cozinha e se a gente não puder vir a merendeira nos ajuda (E3).

Porém este fato também pode ser explicado pela falta de profissionais na região, o difícil acesso a cidade e aos custos altos para manter alguns especialistas:

A dificuldade maior de contratar são profissionais com especificações do tipo fonoaudióloga; psicóloga, a gente tem a voluntaria. A terapeuta ocupacional a gente teria que ter... Esses profissionais mais caros aqui não têm na região. Se tu vais pagar alguém que venha de fora, querem cobrar muito caro... e é um pouquinho diferente da nossa realidade. (E1)

As entrevistas relataram uma especificidade da região sobre o voluntariado: na região em que foi realizada a pesquisa não há voluntários nas instituições, justificado pelo receio de reclamatórias trabalhistas. Não assalariados somente os componentes da diretoria administrativa, como a entrevistada E1 explicita:

A questão do voluntário a gente tem muito cuidado: até quando alguém se dispõe a vir, em ser voluntário, a gente procura saber quem é a pessoa, se ela tem uma boa índole, se não tem alguma coisa que vá nos prejudicar. Faz um termo pra poder não ter problemas depois de querer cobrar coisa da gente. Então tem que ser uma coisa bem esclarecida: passa pela psicóloga, a gente tem muito cuidado com isso (E1).

As entrevistas E1 e E2 não relataram nenhuma experiência de formação oferecida aos colaboradores. Somente E4 informou que realiza dentro da associação as formações e E3 comenta que participam de outras atividades de formação, mas fora da associação:

Nós temos as formações na casa onde todos eles participam dessas formações, nós temos reuniões pedagógicas são quinzenais, mais ou menos, de capacitação, de formação, de tudo que vai ser trabalhado na escola [...] o seminário da clínica que a gente traz várias pessoas pra conversar com os professores e ai a gente abre então pra toda rede. (E4)

Para iniciar a APAE duas professoras fizeram a capacitação em educação especial na cidade de Osório. Fazendo uma vez, tu não precisas mais fazer... mas como tudo muda, se quiser fazer para aprender alguma coisa nova, pode. Participamos todo ano de um seminário em relação à educação especial (E3). 
E4 menciona que há meios de buscar desenvolvimento e oportunidades para a equipe de trabalho como na experiência compartilhada:

\footnotetext{
A gente vai, organiza algum transporte, eu,o presidente e mais um pessoal da clinica, e nós vamos a outros lugares, ver como que está a proposta em tal lugar. A gente vai como equipe e uns professores, ai a gente se deparou assim com realidades (E4).
}

\section{CONSIDERAÇÕES FINAIS}

A investigação teve como objetivo identificar especificidades das relações de trabalho no terceiro setor, a partir de uma pesquisa qualitativa do tipo exploratória tendo como instrumentos entrevistas com quatro representantes das APAES da região Centro Sul do RS.

Os processos formais de vínculo no trabalho estão presentes nos procedimentos de contratação e demissão de pessoal, realizado em parceria com prefeituras do município onde estão situadas as APAES. Os municípios cedem profissionais - já que muitas das instituições não têm condições de custear os salários e, de outra parte, não o Estado não oferece os serviços à população. Diferentemente do aspecto majoritário do terceiro setor, nas instituições pesquisadas não há membros voluntários em virtude do receio de ações trabalhistas e reduzida articulação da comunidade.

Os presidentes das APAES estão presentes nas instituições, desde a tomada de decisões, contratação, demissão, captação de recursos e participação em eventos. Os gestores, por sua vez, possuem formação na área pedagógica e seus processos de trabalho junto à equipe são bastante informais, basicamente na direção de enfrentar os problemas e dificuldades da instituição. Outro aspecto evidenciado é o fato de quanto mais recursos à associação possui - aporte financeiro, profissionais em seu quadro pessoal, localização/acessibilidade - melhores são as práticas com seus membros, como capacitações e visitas a outras organizações para buscar melhorias. Os colaboradores atuam em diversas funções, pois o quadro é reduzido e em geral todos realizam multitarefas, respondendo simultaneamente por várias atribuições. 
Futuras pesquisas neste âmbito podem dar visibilidade às diferenças existentes nas instituições do terceiro setor, especialmente considerando as desigualdades de recursos e estruturadessas organizações em diferentes regiões do país e condições sócio-econômicas.

\section{REFERÊNCIAS}

ASSIS, L. B. de; VIEGAS, G.; CKAGNAZAROFF, I. B.. Gestão de Recursos Humanos no Terceiro Setor: Um estudo descritivo das Organizações de Belo Horizonte. REVISTA ELETRÔNICA DE GESTÃO ORGANIZACIONAL, v. 10, n. 02, p. 297 - 323. 2012. Disponível em:<http://www.spell.org.br/documentos/ver/8462/gestao-de-recursos-humanos-noterceiro-setor---um-estudo-descritivo-das-organizacoes--de-belo-horizonte/i/pt-br>. Acesso em: 26 ago. 2015 .

CABRAL, E. H. S. Terceiro Setor: gestão e controle social. São Paulo. Saraiva, 2007

CAVALCANTE, C. E. et al. Motivação para entrada de voluntários em ONG brasileira. Revista de Administração, v. 50, n. 4, p. 523, 2015.

DINIZ, G.S.. Direito das Fundações Privadas. 2. ed. Porto Alegre: Síntese, 2003.

FENAPAES. Manual de fundação das APAES. Brasília, 2014. Disponível emwww.apaebrasil.org.br. Acesso em: 20 ago 2015.

GIL, A. C.. Métodos e técnicas de pesquisa social. 6. ed. São Paulo: Atlas, 2012.

Grupo de Institutos, Fundações e Empresas (GIFE). O Gife. Disponível em: 〈www.gife.org.br〉. Acesso em: 02 set. 2015.

INSTITUTO PRO BONO.Manual do Terceiro Setor.Disponível em: http://www.probono.org.br/publicacoes/manual-do-terceiro-setor. Acesso em: 02 set. 2015. 
LAKATOS, E. M.; MARCONI, M. de A.. Fundamentos de metodologia científica. 5. ed. São Paulo: Atlas, 2003.

MALHOTRA, N. K. Pesquisa de Marketing: uma orientação aplicada. 6. ed. Porto Alegre: Bookman, 2012.

MENESCAL, A.K.. História e gênese das organizações não governamentais. In: GONÇALVES, Hebe Signorini. Organizações não governamentais: solução ou problema. São Paulo: Estação Liberdade, 1996.

PEREIRA, R. S.; MORAES, F. C. C. de; MATTOS, A. B. J.; PALMISANO, A. Especificidades da Gestão no Terceiro Setor.ORGANIZAÇÕES EM CONTEXTO.SÃO BERNARDO DO CAMPO, SP.v. 9, n. 18, p. $167 \quad$ - $195 . \quad 2013 . \quad$ Disponível em: <http://www.spell.org.br/documentos/ver/21158/especificidades-da-gestao-no-terceiro-setor/i/ptbr>. Acesso em: 01 set. 2015.

PINTO, C. R. J.. As ONGs e a política no Brasil: presença de novos atores. Dados, Rio de Janeiro, v. $49, \mathrm{n} . \quad 3, \mathrm{p}$ 651-670, $2006 . \quad$ Disponível em $<$ http://www.scielo.br/scielo.php?script=sci_arttext\&pid=S001152582006000300008\&lng=pt\&nrm=iso>. acessos em $05 \quad$ dez. 2015 . http://dx.doi.org/10.1590/S0011-52582006000300008.

SOARES, A. C. A. A.; MELO, M. C. O. L. Gestão do Terceiro Setor: Uma Prática Social? REVISTA DE GESTÃo USP. São Paulo, SP. v.17, n.1, p.1- 11, 2010. Disponível em: $<$ http://www.spell.org.br/documentos/ver/5310/gestao-do-terceiro-setor--uma-pratica-social-/i/ptbr>. Acesso em: 02 set. 2015.

SILVA, C. E. G.. Gestão, legislação e fontes de recursos no terceiro setor brasileiro: uma perspectiva histórica. REVISTA DE ADMINISTRAÇÃO PÚBLICA. Rio de Janeiro, RJ. v. 44, n. $\quad 6, \quad$ p. $\quad 1301-1325,2010 . \quad$ Disponível 
em: <http://www.scielo.br/scielo.php?script=sci_arttext\&pid=S0034-76122010000600003>. Acesso em: 31 ago. 2015.

TACHIZAWA, T.. Organizações não governamentais e Terceiro Setor: Criação de ONGs e estratégias de atuação. 4. ed. São Paulo: Atlas, 2010.

TACHIZAWA, T.; POZO, H.; ALVES, J. A. F.. Formulação de um Plano Estratégico em Instituições do Terceiro Setor: O Caso de Uma ONG de Pequeno Porte. REUNA. Belo Horizonte, MG. v. 17, n. 3, p. 53 - $72 . \quad$ 2012. Disponível em: $<$ http://www.spell.org.br/documentos/ver/9037/formulacao-de-um-plano-estrategico-eminstituicoes-do-terceiro-setor--o-caso-de-uma-ong-de-pequeno-porte/i/pt-br>. Acesso em: 01 set. 2015.

TENÓRIO, F. G.. (Org.). Gestão de ONGs: principais funções gerenciais. 8. ed. Rio de Janeiro: FGV, 2004.

\footnotetext{
${ }^{1}$ Graduada em Gestão de Recursos Humanos pelo Centro Universitário La Salle Canoas. E-mail: amandaburchert@gmail.com

${ }^{2}$ Doutora em Psicologia Social pela USP. Docente e coordenadora do curso de Gestão de RH no Centro Universitário La Salle Canoas; docente e pesquisadora no programa de pós graduação em Educação na mesma instituição. Email: denise.ziliotto@unilasalle.edu.br

${ }^{3}$ Sertão Santana - 6.008 habitantes, Barão do Triunfo - 6.767 habitantes, Barra do Ribeiro - 13.039 habitantes Camaquã - 65.745 habitantes.
}

RECEBIDO EM: Abril de 2016

APROVADO EM: Junho de 2016 